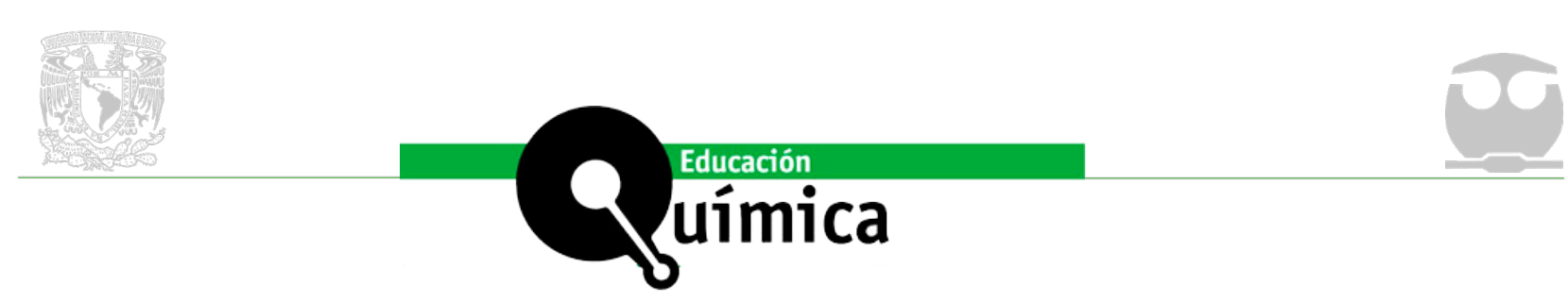

\title{
Aprendizaje conceptual del tema concentración de disoluciones: análisis de imágenes de libros de texto universitario
}

\author{
Andrés Raviolo ${ }^{1}$ Andrea Farré ${ }^{2}$
}

\section{Resumen}

En este artículo se realiza una breve discusión en torno al rol de las imágenes en el aprendizaje y al papel que juegan en los libros de texto. También se lleva adelante una revisión de las principales dificultades y concepciones alternativas que presentan estudiantes de nivel medio y universitario en el aprendizaje del tema concentración de disoluciones y, sobre esta base, se especifican los aspectos conceptuales deseables a ser abordados en la enseñanza de este tema. Posteriormente se indaga si estos aspectos son tenidos en cuenta en explicaciones o ejercicios que empleen imágenes en libros de texto de primer año de universidad. Se analizaron 25 libros de química general editados entre los años 2000-2020, hallándose que los textos editados en los últimos 10 años han duplicado el número de imágenes sobre aspectos conceptuales de concentración, con respecto a los 10 años anteriores, y que ha aumentado el uso de diagramas de partículas. Se discuten las implicancias educativas de los resultados encontrados.
Palabras clave

Imágenes, Libros de texto, Concentración disoluciones, Abordaje conceptual.

\section{Conceptual learning of the topic concentration of solutions: image analysis from university textbooks}

\begin{abstract}
This article offers a brief discussion about the impact of images in learning and the role they play in textbooks. A review of the main difficulties and alternative conceptions presented by middle and university students in learning of the topic concentration of solutions is also carried out and, on this basis, the desirable conceptual aspects to be addressed in teaching this topic are specified. Subsequently, it is examined whether these aspects are taken into account in explanations or exercises that use images in textbooks of the first year of university. Twenty five general chemistry books published between the years 2000-2020 were analyzed, finding that the texts published in the last 10 years have doubled the number of images on conceptual aspects of concentration, compared to the previous ten years, and that the use of diagrams of particles has increased. The educational implications of the results found are discussed.
\end{abstract}

\section{Keywords}

Images, Textbooks, Concentration solutions, Conceptual approach

${ }^{1}$ Universidad Nacional de Río Negro. Bariloche. Argentina. Correo: araviolo@unrn.edu.ar

${ }^{2}$ Universidad Nacional de Río Negro. Bariloche. Argentina. Correo: asfarre@unrn.edu.ar 


\section{Introducción}

$\mathrm{E}$ 1 tema disoluciones es básico en el currículo de química, tanto en nivel medio como universitario. Los estudiantes, como se expondrá más adelante, presentan dificultades tanto en los aspectos cualitativos sobre la naturaleza de las disoluciones como en aspectos cuantitativos al enfrentar situaciones donde deben aplicar el concepto de concentración.

Una disolución es una mezcla homogénea formada por dos o más componentes. Los componentes que se encuentran en menor proporción se denominan solutos y el de mayor proporción, que dispersa al soluto, se denomina solvente. Generalmente se consideran disoluciones formadas por un soluto y un solvente (Ej. cloruro de sodio en agua, azúcar en agua). La proporción entre la cantidad de soluto con respecto a la cantidad de solución, o a la cantidad de solvente, se denomina concentración. La concentración se expresa en distintas unidades, las más comunes son: gramos de soluto por litro de disolución, gramos de soluto por cada $100 \mathrm{~mL}$ de disolución, gramos de soluto por cada $100 \mathrm{~g}$ de solución, moles de soluto por litro de disolución (molaridad o concentración molar) y moles de soluto por kilogramo de solvente (molalidad).

La enseñanza del tema concentración se basa casi en exclusiva en la presentación de ejercicios numéricos sobre las distintas unidades de concentración y en el empleo de fórmulas como la de molaridad $(M=n / V)$. Este trabajo tiene como objetivo identificar y llamar la atención sobre el tipo de imágenes que pueden apoyar un abordaje cualitativo/ conceptual del tema concentración que permita a los estudiantes enfrentar exitosamente problemas y situaciones.

\section{Imágenes y aprendizaje}

Un enfoque que puede ayudar a comprender cómo los estudiantes aprenden desde las imágenes, que se presentan en un libro de texto, es la teoría cognitiva del aprendizaje multimedia (Mayer, 2009). Esta teoría sostiene la premisa "se aprende más profundamente una información si es presentada con palabras e imágenes más que con palabras solas". El término multimedia se refiere a presentaciones o comunicaciones que incluyen palabras e imágenes orientadas a fomentar aprendizajes, es decir, se circunscribe a imágenes con fines educativos.

Esta teoría se opone a la costumbre de asumir que el principal medio para transmitir información es la palabra (escrita o hablada) y define los roles del alumno y del profesor. El aprendiz construye conocimiento en un proceso activo de aprendizaje, asentado en su esfuerzo de dar sentido a la información, lo que implica: (a) seleccionar el material relevante, (b) organizarlo en representaciones coherentes, (c) establecer conexiones entre las representaciones verbales y pictóricas y (d) integrar el material al conocimiento existente. Por su parte, el profesor apoya y/o fomenta esos procesos cognitivos relevantes, brindando las condiciones para un aprendizaje generativo orientado a construir relaciones mentales entre imágenes, palabras y conocimiento previo (Mayer, 2008).

Basado en una rigurosa evidencia empírica, Mayer formula 12 principios que optimizan el aprendizaje de material multimedia. Estos principios se aplican especialmente cuando el material a ser comprendido es complejo y cuando el aprendiz no dispone, o tiene poco, conocimiento previo. Por ello estos principios son muy pertinentes para el caso de la enseñanza de la química, porque es la situación que se presenta en las aulas. 
Dos principios resultan relevantes para el caso del aprendizaje a partir de libros de texto: (a) el principio de contigüidad espacial que sostiene que se aprende mejor la información cuando el texto, y su imagen correspondiente, están físicamente integrados en el texto. Es decir, la explicación de una figura debe estar cerca de la misma, los rótulos de cada parte cercanos a lo que nombra. Este principio es, en la actualidad, generalmente tenido en cuenta por los diseñadores de libros de texto y (b) el principio de la coherencia que afirma que se aprende mejor una información cuando material extraño es excluido más que cuando es incluido. O sea, es conveniente excluir palabras e imágenes irrelevantes, por más que puedan ser interesantes y prescindir de símbolos innecesarios y de exceso de detalles. La interferencia de material innecesario puede desviar la atención de las ideas centrales y/o saturar la capacidad de procesamiento. Por ejemplo, en la mayoría de imágenes con partículas que abordan el concepto de concentración de disoluciones acuosas, las moléculas de agua no se representan, con el fin de mejorar la claridad de las mismas y orientar a atención al aspecto que se intenta resaltar. Otras implicancias de esta teoría y de los principios del aprendizaje multimedia, para la enseñanza de la química, han sido desarrolladas en el artículo de Raviolo (2019).

\section{Imágenes y libros de texto}

Los libros de texto de química tienen un origen relativamente reciente en la historia del conocimiento. Los primeros tratados fueron escritos con la intención principal de dar a conocer los resultados de investigación a los colegas más que con un fin didáctico. El crecimiento de los saberes disciplinares, el establecimiento de mayores acuerdos entre la comunidad de científicos y la necesidad de formación de recursos humanos especializados, dieron lugar a la publicación de los libros de texto hacia finales del 1800. Estos nuevos textos intentaban compilar la mayor cantidad de información disponible surgida cada vez más vertiginosamente de los desarrollos de la química. Sin embargo, esta carrera contra el tiempo fue alejando a los libros de texto de los escenarios de investigación (Chamizo, 2007).

Aún hoy en la era de la virtualidad, los libros de texto continúan vigentes en los sistemas de enseñanza como materiales didácticos, utilizados como apoyo para el aprendizaje de los alumnos. En particular, en la práctica universitaria suele considerarse como acompañantes del aprendizaje autónomo. Consecuentemente, los estudiantes deberían poseer los conocimientos previos necesarios para entender el significado de nuevas categorías semánticas y modos diversos de presentación. Por ejemplo, para inferir la información implícita en un texto a través de un lenguaje impersonal, literal, preciso, correspondiente a hechos aceptados en el seno de la comunidad científica (Sutton, 1997).

A lo largo de los años, los libros de texto de química, evidencian un notable aumento en el número y calidad de las imágenes que han incorporado, con una mayor tendencia a cumplir funciones explicativas más que funciones decorativas (Raviolo, 2016). Entre estas imágenes se destacan los diagramas y dibujos esquemáticos. Los diagramas son ilustraciones simplificadas o esquemáticas en los que prima la representación de las relaciones prescindiendo de los detalles. Por su parte, los dibujos esquemáticos (Perales y Jiménez, 2002) son un tipo de diagrama en los que alguna parte (o partes) del dibujo se corresponden a partes de algún objeto real o entidad. Alguna parte es figurativa, es decir, está presente el nivel de representación macroscópico de la materia. En química estos dibujos también suelen incluir otros niveles de representación como el nivel submicroscópico y el nivel simbólico (Solaz, 1996; Raviolo, 2015). 
Se ha señalado (Souza y Porto, 2012) que el uso de este tipo de imágenes se debe a la promoción de una mayor teorización y abstracción de la disciplina en desmedro de su dimensión práctica y experimental. Consistente, además, con la presentación de la química como un cuerpo de conocimientos con una estructura sólida conformada por principios generales. Entre las décadas de 1940 y 1960, existió un aumento en los gráficos y diagramas que representan modelos e imágenes relacionadas con lo fenomenológico y lo teórico-conceptual, en detrimento de las figuras de los equipamientos de laboratorio y de los procedimientos experimentales e industriales. Independientemente de cuál fuera la causa de la presencia de las imágenes, como se indicaba en el apartado anterior, su interpretación no es natural. Se requiere un procesamiento particular que si se lo realiza puede potenciar el aprendizaje de cualquier tema de química, y también en nuestro caso del concepto de concentración.

\section{Dificultades y concepciones alternativas en el aprendizaje de concentración}

La mayoría de las investigaciones dirigidas a detectar dificultades en los estudiantes sobre el tema disoluciones se han centrado en aspectos cualitativos como la naturaleza de las disoluciones y el proceso de disolución más que en sus aspectos cuantitativos (Calyk y otros, 2005). Por ejemplo, se encontró que estudiantes de secundaria perciben el proceso de disolver como una fusión (Ebenezer y Erickson, 1996) o que el soluto literalmente desaparece (Lee et al., 1993). De hecho no se encuentran artículos que hallan abordado, en forma exclusiva y en profundidad, el concepto de concentración; más bien, el aprendizaje de este concepto ha sido indagado formando parte de investigaciones más amplias, que en su mayoría se ocuparon de una única unidad de concentración: la molaridad. Respecto a molaridad, se hallan investigaciones centradas en: estequiometría y mol (Dahsah y Coll, 2008; Johnstone, 1983; Khang y Sai, 2008), titulaciones (Anamuah-Mensah, 1986; Frazer y Servant, 1986), equilibrio químico (Quílez, 2008), resolución de problemas (de Berg, 2012; Heyworth, 1999; Niaz, 1995) y razonamiento proporcional (Gabel et al., 1984; Ryan, 2012).

En la Tabla 1 se presenta una síntesis de las principales confusiones o concepciones alternativas que se han evidenciado con estudiantes de diferentes niveles educativos. Se emplea el término concepción alternativa para describir ideas que difieren o son inconsistentes con las concepciones aceptadas por la comunidad científica. Además, se detalla si en la investigación se emplearon imágenes submicroscópicas para indagarlas.

Tabla 1. Concepciones y dificultades sobre el concepto de concentración

\begin{tabular}{llcc}
\multicolumn{1}{c}{ Concepción o dificultad } & \multicolumn{1}{c}{ Investigación } & \multicolumn{1}{c}{$\begin{array}{c}\text { Nivel } \\
\text { educativo }\end{array}$} & $\begin{array}{l}\text { Incluye imágenes } \\
\text { submicroscópicas }\end{array}$ \\
$\begin{array}{l}\text { Confunden número de moles con } \\
\text { molaridad }\end{array}$ & $\begin{array}{l}\text { Johnstone (1983) } \\
\text { Heyworth (1999) }\end{array}$ & Medio & No \\
\hline $\begin{array}{l}\text { Presentan confusiones sobre lo que ocurre } \\
\text { con la concentración ante el agregado de } \\
\text { agua a la solución (dilución) o ante su } \\
\text { evaporación }\end{array}$ & $\begin{array}{l}\text { Gabel y Samuel } \\
(1986)\end{array}$ & Medio & Medio \\
\hline $\begin{array}{l}\text { Sostienen que a mayor cantidad de soluto } \\
\text { hay menor o igual concentración (a } \\
\text { cantidad de solvente igual) }\end{array}$ & Calik (2005) & & No \\
\hline
\end{tabular}




\begin{tabular}{|c|c|c|c|}
\hline $\begin{array}{l}\text { Asumen que la concentración depende del } \\
\text { volumen de la disolución y no de la relación } \\
\text { entre cantidad de soluto y volumen de } \\
\text { solvente o solución }\end{array}$ & $\begin{array}{l}\text { Dahsah y Coll } \\
(2008)\end{array}$ & Medio & No \\
\hline $\begin{array}{l}\text { Muestran dificultades en el razonamiento } \\
\text { proporcional cuando cambian ambas } \\
\text { variables: el número de partículas y el } \\
\text { volumen de disolución }\end{array}$ & $\begin{array}{l}\text { Devetak et al. } \\
(2009)\end{array}$ & Medio & $\mathrm{Si}$ \\
\hline $\begin{array}{l}\text { Conciben a las representaciones de } \\
\text { moléculas de azúcar como granos sin } \\
\text { disolver y por ello, con el agregado de agua, } \\
\text { disminuye el número de granos no disueltos }\end{array}$ & $\begin{array}{l}\text { Adadan y Savasci } \\
(2012)\end{array}$ & Medio & $\mathrm{Si}$ \\
\hline $\begin{array}{l}\text { Afirman que si se extrae parte del volumen } \\
\text { de la disolución, la cantidad de soluto por } \\
\text { unidad de volumen aumenta }\end{array}$ & $\begin{array}{l}\text { Adadan y Savasci } \\
(2012)\end{array}$ & Medio & $\mathrm{Si}$ \\
\hline $\begin{array}{l}\text { No asumen la constancia del número de } \\
\text { moles de soluto ante una dilución }\end{array}$ & Niaz (1995) & Universitario & No \\
\hline $\begin{array}{l}\text { Mediante cálculos, ante una dilución, arriban } \\
\text { a una concentración mayor a la original }\end{array}$ & Níaz (1995) & Universitario & No \\
\hline $\begin{array}{l}\text { Conciben que la molaridad es proporcional } \\
\text { al volumen de disolución, no la conciben } \\
\text { como propiedad intensiva de la misma }\end{array}$ & Ryan (2012) & Universitario & No \\
\hline $\begin{array}{l}\text { Presentan dificultades al aplicar la } \\
\text { proporcionalidad inversa en situaciones } \\
\text { donde tienen que relacionar el número } \\
\text { de moles y la M para determinar qué } \\
\text { disolución ocupa un menor volumen }\end{array}$ & $\begin{array}{l}\text { Raviolo y Farré } \\
\text { (2018) }\end{array}$ & Universitario & No \\
\hline $\begin{array}{l}\text { Focalizan solo en el número de partículas } \\
\text { de soluto y no en el número de partículas } \\
\text { por unidad de volumen }\end{array}$ & de Berg (2012) & Universitario & $\mathrm{Si}$ \\
\hline $\begin{array}{l}\text { Afirman que las moléculas de soluto } \\
\text { desaparecen o no están distribuidas } \\
\text { homogéneamente }\end{array}$ & de Berg (2012) & Universitario & $\mathrm{Si}$ \\
\hline
\end{tabular}

\section{Aprendizaje conceptual del tema concentración}

Se aprecia en el apartado anterior que los estudiantes mantienen dificultades sobre el tema concentración después de su enseñanza, por más que puedan arribar a respuestas correctas en ejercicios numéricos. Es necesario que los estudiantes cuenten con un conocimiento conceptual profundo, con un conocimiento cualitativo, que vaya más allá del manejo de fórmulas y números, basado en representaciones mentales apropiadas.

Sobre la base de lo desarrollado, se enumeran a continuación los aspectos conceptuales del tema concentración a los que habría que prestar atención en la enseñanza:

- homogeneidad de la disolución: el soluto está uniformemente distribuido en todo el volumen de la mezcla. La concentración es la misma en toda la disolución.

- homogeneidad a nivel submicroscópico: las partículas de soluto (iones, moléculas) están distribuidas uniformemente en el volumen considerado.

- concepto: la concentración es la cantidad de soluto por unidad de volumen de disolución (también puede expresarse por unidad de masa, de solvente o de solución). 
- concepto a nivel submicroscópico: la concentración es cantidad de partículas de soluto por unidad de volumen de disolución.

- intensividad: la concentración es una propiedad intensiva: no depende de la cantidad de disolución considerada. La concentración no varía en procesos como transferencia de una parte de una disolución, transferencia de la totalidad a otro recipiente con otra forma o agregado de un volumen de la misma concentración.

- extensividad del soluto: el número de unidades de soluto dependen de la cantidad de disolución considerada.

- extensividad del volumen: el número de unidades de volumen dependen de la cantidad de disolución considerada.

- relación directamente proporcional: la concentración es directamente proporcional a la cantidad de soluto, a volumen de disolución constante.

- relación inversamente proporcional: la concentración es inversamente proporcional al volumen de disolución, a cantidad de soluto constante.

- proporción: la concentración de una disolución no se modifica ante el agregado de soluto y el agregado de solvente si lo hacen manteniendo la proporción

- preparación: el proceso experimental con el cual se logra una disolución con la proporción o concentración deseada.

- efecto dilución: la concentración de la disolución disminuye con el agregado de más solvente, a cantidad de soluto constante.

- efecto concentración: la concentración de la disolución aumenta ante la evaporación de solvente, a cantidad de soluto constante.

\section{Pregunta de investigación}

¿Qué imágenes presentan los libros de texto universitario que aborden aspectos conceptuales de concentración?

\section{Metodología}

La muestra consistió en 25 de libros de texto de primer año de universidad (Tabla 2). Se indagó en el capítulo o apartado sobre concentración de disoluciones donde se define concentración, se presentan las distintas unidades y las formas de prepararlas. También se indagó en el apartado de problemas que se presentan al final de dicho capítulo.

Si bien la muestra no es exhaustiva, abarca los principales textos que se emplean en cursos de Introducción a la Química y Química General. Se incluyen libros en español y en inglés a los que se pudo tener acceso, con fecha de edición posterior al año 2000.

Tabla 2 Muestra de libros indagados

\begin{tabular}{|c|c|c|c|}
\hline Autor & Título & Edición & Año \\
\hline Burdge & Chemistry & 5 & 2020 \\
\hline Tro & Chemistry & 15 & 2020 \\
\hline Chang y Goldsby & Química & 12 & 2017 \\
\hline Timberlake y Timberlake & Basic Chemistry & 5 & 2017 \\
\hline Whitten y otros & Química & 10 & 2015 \\
\hline
\end{tabular}




\begin{tabular}{|c|c|c|c|}
\hline Talbot y otros & Chemistry & 2 & 2015 \\
\hline Russo y Silver & Introductory Chemistry & 5 & 2015 \\
\hline Brown y otros & Química & 12 & 2014 \\
\hline Suchocki & Conceptual Chemistry & 5 & 2014 \\
\hline Atkins y otros & Chemical principles & 6 & 2013 \\
\hline Zundalh y DeCoste & Principios de Química & 7 & 2012 \\
\hline American Chemical Society (ACS) & Chemistry in Context & 7 & 2012 \\
\hline Petrucci y otros & Química General & 10 & 2011 \\
\hline Burns & Fundamentos de Química & 5 & 2011 \\
\hline Ebbing y Gammon & Química General & 9 & 2010 \\
\hline Poulsen & Introduction to Chemistry & & 2010 \\
\hline Silberberg & Chemistry & 5 & 2009 \\
\hline Mc Murry y Fay & Química & 5 & 2009 \\
\hline Goldberg & Fundamentals of Chemistry & 5 & 2006 \\
\hline Hein y Arena & Foundations of College Chemistry & 12 & 2006 \\
\hline Daub y otros & Química & 8 & 2005 \\
\hline American Chemical Society (ACS) & Química & & 2005 \\
\hline Myer y otros & Chemistry & & 2004 \\
\hline Phillips y otros & Chemistry & & 2002 \\
\hline Umland y Bellama & Química General & 3 & 2000 \\
\hline
\end{tabular}

Las imágenes se copiaron, escanearon o fotografiaron y se incorporaron en un archivo para su posterior análisis y clasificación.

\section{Resultados}

Se halló un total de 80 imágenes en los 25 libros de texto. Un promedio de 3.2 figuras por texto. Los libros que más figuras incluyeron fueron: Russo y Silver (12), Burdge (9) y Timberlake y Timberlake (7). Catorce libros incluyeron diagramas con partículas. Si analizamos los textos más actuales (2012-2020) se hallan 51 imágenes en 12 textos, con un promedio de 4.3 figuras por texto; 8 de esos textos incluyen diagramas de partículas. En cambio, en los 13 textos del período (2000-2011) se hallaron 29 imágenes, con un promedio de 2.2 figuras por libro; 6 textos incluyen diagramas con partículas.

Atendiendo a los objetivos de esta exploración, las imágenes relevadas (fotos, dibujos y diagramas) relacionadas con el concepto de concentración fueron clasificadas en:

A. Fotos de disoluciones de distintas concentraciones del mismo soluto que se perciben por diferente intensidad de color

B. Fotos de disoluciones de distintas concentraciones que se perciben por diferente intensidad de color con imagen microscópica en círculo magnificado

C. Fotos o dibujos del procedimiento de preparar una disolución ( $\% \mathrm{~m} / \mathrm{V}$ o $\mathrm{M})$ en un matraz aforado a partir del soluto sólido

D. Fotos o dibujos del procedimiento de preparar una disolución en M, en un matraz aforado a partir de una disolución de mayor concentración

E. Fotos o dibujos del procedimiento de preparar una disolución en otra concentración $(\% \mathrm{~m} / \mathrm{m}, \mathrm{m})$ o a partir del soluto líquido (ej. alcohol etílico) 
F. Imagen microscópica antes y después de una dilución empleando recipiente (ej. vaso de precipitado) mostrando las partículas de soluto "inmersas" en el líquido

G. Imagen microscópica antes y después de una dilución empleando círculo magnificado

H. Diagrama de ejercicio conceptual que relaciona macroscópicamente las variables cantidad de soluto, volumen de disolución y concentración

I. Diagramas con partículas en ejercicio conceptual

Con estas categorías se abarcaron la totalidad de las imágenes encontradas. Las imágenes halladas por texto y categorías se muestran en la Tabla 3:

Tabla 3 Resultados del análisis bibliográfico

\begin{tabular}{|c|c|c|c|c|c|c|c|c|c|}
\hline Autor & $\mathbf{A}$ & B & C & D & $\mathbf{E}$ & $\mathbf{F}$ & G & $\mathbf{H}$ & I \\
\hline Burdge & $\mathrm{x}$ & $\mathrm{x}$ & $\mathrm{x}$ & & & & $\mathrm{x}$ & $\mathrm{x}$ & $\mathrm{x}$ \\
\hline Tro & & $\mathrm{x}$ & $\mathrm{x}$ & $\mathrm{x}$ & & & & & \\
\hline Chang y Goldsby & $\mathrm{x}$ & & $\mathrm{x}$ & & & $\mathrm{x}$ & & & \\
\hline Timberlake y Timberlake & & & $\mathrm{x}$ & & $\mathrm{x}$ & & $\mathrm{x}$ & $\mathrm{x}$ & \\
\hline Whitten y otros & & & $\mathrm{x}$ & & & & $\mathrm{x}$ & $\mathrm{x}$ & $\mathrm{x}$ \\
\hline Talbot y otros & $\mathrm{x}$ & & $\mathrm{x}$ & & & & & & \\
\hline Russo y Silver & & & $\mathrm{x}$ & $\mathrm{x}$ & $\mathrm{x}$ & $\mathrm{x}$ & & $\mathrm{x}$ & \\
\hline Brown y otros & & & $\mathrm{x}$ & $\mathrm{x}$ & & & & & \\
\hline Suchocki & & & $\mathrm{x}$ & & & & & & \\
\hline Atkins y otros & & & $\mathrm{x}$ & & & $\mathrm{X}$ & $\mathrm{x}$ & & \\
\hline Zundalh y DeCoste & & & $\mathrm{x}$ & $\mathrm{x}$ & & & & & $\mathrm{x}$ \\
\hline ACS & & & $\mathrm{x}$ & & & & & & \\
\hline Petrucci y otros & & & & & $\mathrm{x}$ & & & & \\
\hline Burns & & & $\mathrm{x}$ & & & & & & \\
\hline Ebbing Gammon & & & & $\mathrm{x}$ & $\mathrm{x}$ & $\mathrm{x}$ & & & $\mathrm{X}$ \\
\hline Poulsen & & & & & & & & & $\mathrm{x}$ \\
\hline Silberberg & & & $\mathrm{x}$ & & & & $\mathrm{x}$ & & $\mathrm{X}$ \\
\hline \multicolumn{10}{|l|}{ Mc Murry y Fay } \\
\hline Goldberg & & & & & & & & $\mathrm{x}$ & \\
\hline Hein y Arena & & & $\mathrm{x}$ & & & & & & \\
\hline Daub y otros & & & $\mathrm{x}$ & $\mathrm{x}$ & $\mathrm{x}$ & & & & \\
\hline $\mathrm{ACS}$ & & $\mathrm{x}$ & & & & & & & \\
\hline Myer y otros & & & $\mathrm{x}$ & & & & & & $\mathrm{X}$ \\
\hline Phillips y otros & $\mathrm{x}$ & & $\mathrm{x}$ & & & & & & \\
\hline Umland y Bellama & & & $\mathrm{x}$ & $\mathrm{x}$ & & $\mathrm{x}$ & & & \\
\hline
\end{tabular}

A continuación se presentan ejemplos de imágenes de algunas categorías, destacando cuáles de los aspectos conceptuales mencionados afronta.

B. Fotos de disoluciones de distintas concentraciones que se perciben por diferente intensidad de color con imagen submicroscópica en círculo magnificado. 


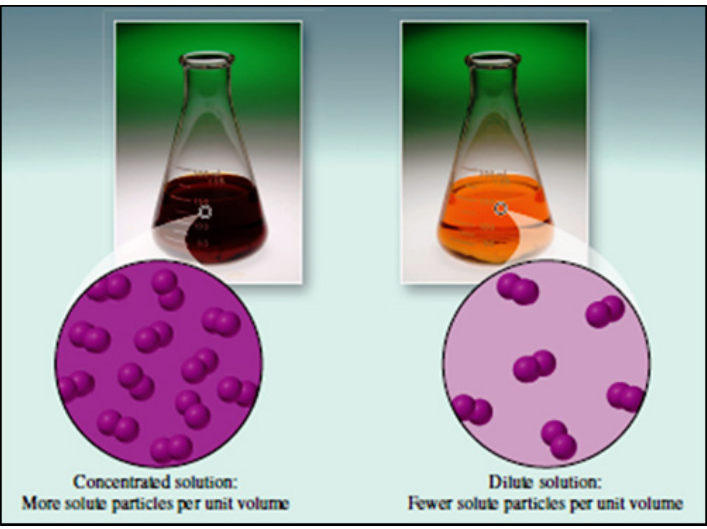

Figura 1: Imagen pág. 154 de Burdge.

Aspectos conceptuales abarcados: homogeneidad, concepto de concentración a nivel micro, relación directamente proporcional. Limitaciones: combinación de aspectos macroscópicos (como el color de fondo) y microscópicos (moléculas) en los círculos magnificados. No se aclara que los distintos círculos magnificados muestran iguales volúmenes.

C. Fotos o dibujos del procedimiento de preparar una disolución ( $\% \mathrm{~m} / \mathrm{V}$ o $\mathrm{M})$ en un matraz aforado a partir del soluto sólido.

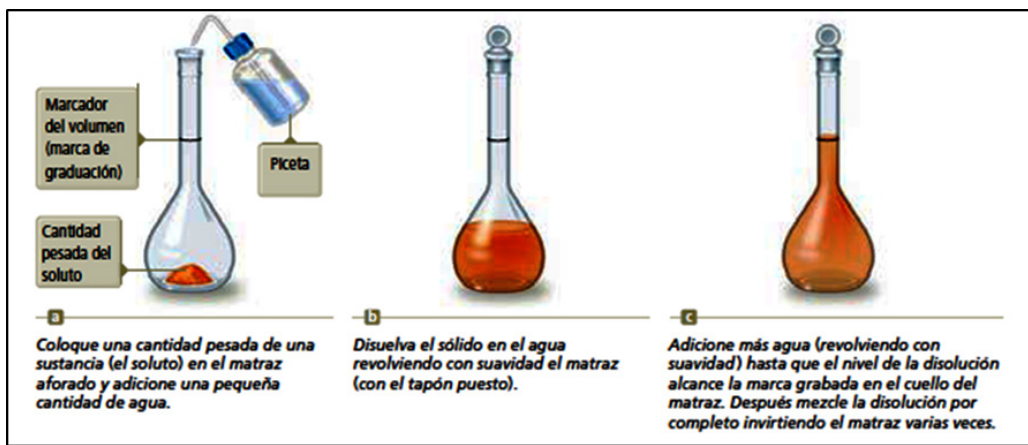

Figura 2: Imagen pág. 487 de Zundalh y DeCoste.

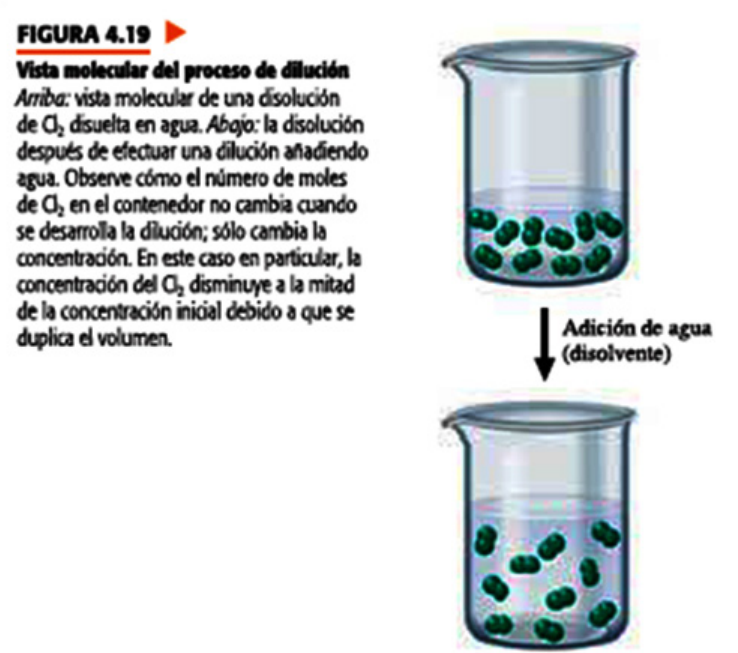

Figura 3: Imagen pág. 157 de Ebbing y Gammon.
Aspectos conceptuales abarcados: homogeneidad, concepto, preparación. Es importante en las figuras que muestran procesos que estén indicadas las etapas mediante numeración o mediante flechas. También que se explique la secuencia en el texto que acompaña la figura.

F. Imagen micro antes y después de una dilución empleando recipiente (ej. vaso de precipitado) mostrando las partículas de soluto "inmersas" en el líquido.

Aspectos conceptuales abordados: homogeneidad a nivel micro, concepto a nivel micro, relación inversamente proporcional, efecto dilución. Limitación: combinación de aspectos macroscópicos (bordes de recipiente, superficie horizontal del líquido) con submicroscópicos. Da la impresión de moléculas de soluto en un medio o materia continua. 
G. Imagen submicroscópica antes y después de una dilución empleando círculo magnificado.

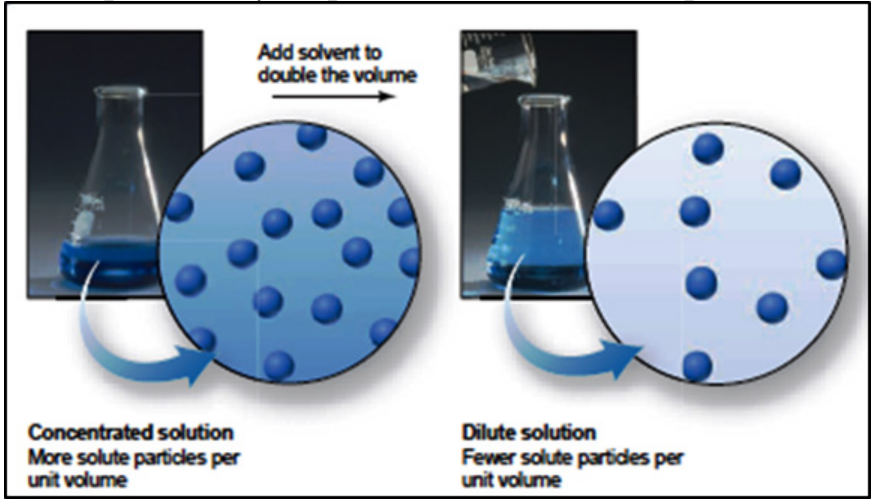

Figura 4: Imagen pág. 123 de Silberberg.

99. En un matraz volumétrico de $1 \mathrm{~L}$ colocó $58.44 \mathrm{~g} \mathrm{de} \mathrm{NaCl}$, agregó agua hasta disolver y, al final, el matraz quedó como el de la ilustración. La molaridad de la solución que preparó

a) es mayor que $1 M$ porque agregó más solvente del necesario.

b) es menor que $1 M$ porque agregó menos solvente del necesario.

c) es mayor que $1 M$ porque agregó menos solvente del necesario.

d) es menor que $1 M$ porque agregó más solvente del necesario.

e) es $1 M$ porque la cantidad de soluto, no de solvente, determina la concentración.

Figura 5: Imagen pág. 113 de Whitten.
Aspectos conceptuales abarcados: homogeneidad a nivel micro, concepto de concentración a nivel micro, efecto dilución. Limitaciones: combinación de aspectos macroscópicos (como el color de fondo) y microscópicos en los círculos magnificados. No se aclara que los distintos círculos magnificados muestran iguales volúmenes.

H. Diagrama de ejercicio conceptual que relaciona macroscópicamente las variables cantidad de soluto, volumen de disolución y concentración.

Aspectos conceptuales abarcados: concepto de concentración, relación inversamente proporcional, preparación.

I. Diagramas con partículas en ejercicio conceptual

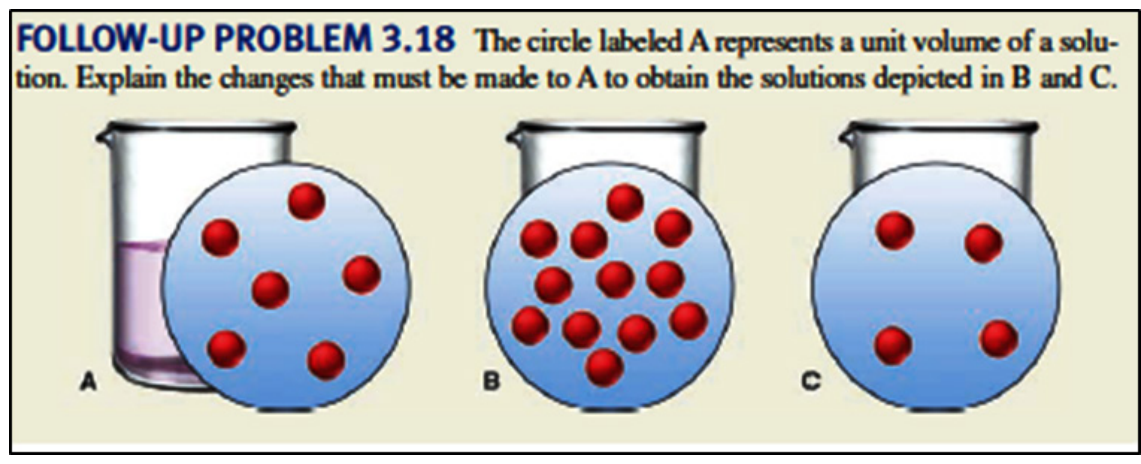

Figura 6: Imagen pág. 125 de Silberberg.

Aspecto conceptual abarcado: homogeneidad a nivel micro, concepto a nivel micro, relación directamente proporcional, efecto dilución, efecto concentración. 


\section{Discusión}

Si bien en los últimos 20 años se aprecia una tendencia ascendente en el número de imágenes explicativas en los libros de texto, todavía el número es exiguo si se pretende abarcar los aspectos conceptuales del tema concentración. En particular, es escaso el número de figuras que contienen diagramas de partículas (categorías B, F, G, I). Para el caso de concentración, estas representaciones deben hacer frente al hecho de que algunos estudiantes focalizan en el número de partículas más que en el número de partículas por unidad de volumen (Devetak y otros, 2009 y de Berg, 2012), es decir, resaltar el concepto de concentración a nivel submicroscópico.

Para Pozo et al., (1991) el hecho de que los estudiantes no utilicen en forma espontánea la idea de partícula en sus explicaciones ante situaciones con disoluciones se debe a dificultades relacionadas con las nociones de continuidad y discontinuidad de la materia. Desde la década de los 80 se viene sugiriendo la presentación sistemática de descripciones con diagramas de partículas (por ejemplo, en el artículo de Gabel, Samuel y Hunn, 1987) sin embargo, su implementación en el tema concentración de disoluciones sigue siendo limitado.

Los libros de texto suelen mostrar visiones moleculares de una disolución, generalmente moléculas de agua rodeando a algún soluto disuelto, por ejemplo el proceso de dilución de $\mathrm{NaCl}$, pero presentan pocas situaciones conceptuales sobre concentración en las que aparezcan iones y moléculas de soluto. Algunas representaciones, si bien están orientadas a mejorar la comprensión del concepto concentración a nivel submicroscópico, resultan confusas, especialmente las que circunscriben las moléculas en un volumen macro, delimitado por las paredes del recipiente y la superficie horizontal de la disolución líquida. Este hecho fue señalado por Andersson (1990) como fuente de concepciones erróneas, dado que dificulta en el estudiante discernir qué es lo que "realmente se ve". Por ello, es mejor que se encuentren bien diferenciadas en la imagen la "zona micro" de la "zona macro"; por ejemplo, utilizando el círculo magnificado, que delimita la visión a nivel submicroscópico.

En la enseñanza basada en diagramas con partículas es importante consensuar en la información implícita contenida, lo que representa el simbolismo empleado y las convenciones utilizadas en su diseño (Raviolo, 2019), dado que muchas de las dificultades pueden deberse a cuestiones de interpretación más que a confusiones relacionadas al concepto de concentración. Los diagramas de partículas son imágenes abstractas que involucran mucha información implícita, que requiere de explicitación o traducción. El empleo de diagramas de partículas para una disolución acuosa requiere acordar con los estudiantes sobre la siguiente información implícita: (a) el círculo magnificado corresponde a un volumen muy pequeño, el contorno de este círculo no está representando las paredes de un recipiente, (b) las esferitas representan átomos, moléculas o iones, que se encuentran en movimiento, (c) esas partículas son indivisibles en los cambios que se abordan, no son granos, (d) las partículas de soluto están rodeadas de moléculas de agua, (e) las moléculas de agua no se han dibujado para simplificar el dibujo, (f) las partículas de soluto se distribuyen uniformemente en el volumen considerado. En las investigaciones, cuando se compara el número de partículas en dos volúmenes en círculos magnificados no se advierte explícitamente que dichos volúmenes son iguales. Este conjunto de reglas, que constituyen una verdadera sintaxis, generalmente no se explicita. 
Los libros de texto de química presentan a las concentraciones con fórmulas, y en los problemas que muestran resueltos se despeja una incógnita de esa fórmula. A la concentración molar, por ejemplo, la presentan como un factor de conversión, así una concentración $0.50 \mathrm{M}$ de $\mathrm{NaCl}$ es presentada como una razón: 0.50 moles $\mathrm{NaCl} / 1 \mathrm{~L}$ disolución. Saber calcular concentraciones constituye un conocimiento procedimental que puede ser aprendido de forma memorística (Lutter et al., 2019). La resolución de problemas de concentración basada en el uso mecánico de procedimientos algorítmicos, no debe opacar la posibilidad de que los estudiantes puedan despegarse de los números y abstraer las relaciones cualitativas-conceptuales entre las variables involucradas y operar eficientemente con ellas.

Dado que en la búsqueda realizada, en el apartado de problemas al final de los capítulos, se hallaron pocas imágenes que acompañen ejercicios conceptuales sobre concentración, se recomienda, complementariamente al uso sistemático de diagramas con partículas, la presentación de situaciones conceptuales a nivel macroscópico (categoría H). Por ejemplo la siguiente imagen que aborda los aspectos conceptuales de: concepto de concentración, intensividad, extensividad de soluto y de volumen de disolución.

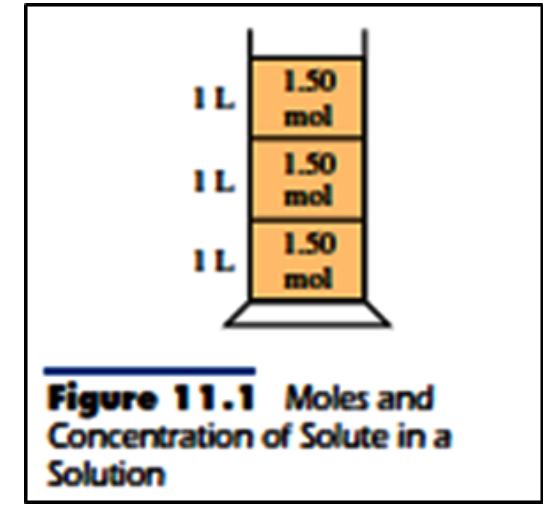

Figura 7: Imagen pág. 294 de Goldberg.

En la figura anterior el texto aclara que en esa imagen es fácil ver que 3.00 litros de solución 1.50 molar contienen 4.50 moles de soluto. Ante estas situaciones formular preguntas del tipo: ¿Qué ocurre con la concentración si se le agregan dos litros de disolución en el que se disolvieron: (a) 1 mol de soluto, (b) tres moles de soluto y (c) cuatro moles de soluto? $\mathrm{O}$ ¿Qué ocurre si el volumen se reduce a 2 litros por evaporación del solvente?

\section{Conclusiones}

El hecho de que la enseñanza de la química se base esencialmente en palabras, símbolos y ecuaciones, contribuye a que los estudiantes no construyan representaciones mentales relacionadas con los niveles macroscópico o submicroscópico de la química. Las imágenes no deben ser concebidas como un acompañamiento superfluo del texto, como un adicional decorativo, sino como un complemento a las palabras, esencial para darles sentido, para crear significados. Es necesario que los profesores y los libros de texto presenten sistemáticamente imágenes explicadas, de modo de ayudar a los alumnos a integrar entre sí representaciones verbales y pictóricas, fomentando que la información tenga sentido e impulsando la vinculación con su conocimiento previo. 
Se ha comprobado que en los últimos 10 años se ha duplicado el número de imágenes sobre el tema, con respecto a los 10 años anteriores y que ha aumentado la cantidad de diagramas de partículas. Sin embargo, todavía no se evidencia que las representaciones submicroscópicas atiendan a todas las dificultades relevadas en la literatura.

El aporte de este artículo no se centra solo en los resultados obtenidos del análisis de textos llevado a cabo, sino en el hecho de definir los aspectos conceptuales de concentración a los que hay que prestar atención y de identificar el tipo de actividades con imágenes que posibilitan su abordaje.

Lo expuesto hasta aquí tiene relevancia e implicancias para la enseñanza en el nivel universitario. Pero también las tiene para el nivel medio, dado que los autores de materiales didácticos para secundaria consultan libros de texto universitarios y porque los mismos docentes los consultan al preparar sus clases.

\section{Bibliografía}

Adadan, E. y Savasci, F. (2012). An analysis of 16-17-year-old students' understanding of solution chemistry concepts using a two-tier diagnostic instrument. International Journal of Science Education, 34, 513-544.

Andersson, B. (1990). Pupils' conceptions of matter and its transformations (age 12-16). Studies in Science Education, 18, 53-85.

Anamuah-Mensah, J. (1986). Cognitive strategies used by chemistry students to solve volumetric analysis problems. Journal of Research in Science Teaching, 23, 759-769.

Calik, M. (2005). A cross-age study of different perspectives in solution chemistry from junior to senior high school. International Journal of Science and Mathematics Education, 3, 671-696.

Calik, M., Ayas, A. y Ebenezer, J. (2005). A review of solution chemistry studies: Insights into students' conceptions. Journal of Science Education and Technology, 14, 29-50.

Chamizo, J. A. (2007). Teaching modern chemistry through 'recurrent historical teaching models'. Science \& Education, 16, 197-216.

de Berg, K. (2012). A study of first-year chemistry students' understanding of solution concentration at the tertiary level. Chemistry Education Research and Practice, 13, 8-16.

Dahsah, C. y Coll, R. (2008). Thai grade 10 and 11 students' understanding of stoichiometry and related concepts. International Journal of Science and Mathematics Education, 6, 573-600.

Devetak, I., Vogrinc, J. y Glažar, S. (2009). Assessing 16-year-old students' understanding of aqueous solution at submicroscopic level. Research Science Education, 39, 157-179.

Ebenezer, J. y Erickson, G. (1996). Chemistry students' conceptions of solubility: A phenomenography. Science Education, 80, 181-201.

Frazer, M y Servant, D. (1986). Aspects of stoichiometry-titration calculations. Education in Chemistry, 23, 54-56.

Gabel, D., Sherwood, R. y Enochs, L. (1984). Problem-solving skills of high school chemistry students. Journal of Research in Science Teaching, 21, 221-233.

Gabel, D. y Samuel, K. (1986). High school students' ability to solve molarity problems and their 
analog counterparts. Journal of Research in Science Teaching, 23, 165-176.

Gabel, D., Samuel, K. y Hunn, D. (1987). Understanding the particulate nature of matter. Journal of Chemical Education, 64(8), 695-697.

Heyworth, R. (1999). Procedural and conceptual knowledge of expert and novice students for the solving of a basic problem in chemistry. International Journal of Science Education, 21, 195-211.

Johnstone, A. (1983). Chemical education research: Facts, findings, and consequences. Journal of Chemical Education, 60, 968-971.

Khang, G. y Sai, C. (2008). Secondary school students' difficulties in learning the "mole concept"A preliminary study in Singapore. Singapore Journal of Education, 8, 80-88.

Lee, O., Eichunger, D., Anderson, C., Berkheimer, G. y Blakeslee, T. (1993). Changing middle school students' conceptions of matter and molecules. Journal of Research in Science Teaching, $30,249-270$.

Lutter, J., Hale, L. y Shultz, G. (2019). Unpacking graduate student's knowledge for teaching solution chemistry concepts. Chemistry Education Research and Practice, 20, 258-269.

Mayer, R. (2008). Learning and instruction (2nd ed.). Upper Saddle River, NJ: Pearson Merrill Prentice Hall.

Mayer, R. (2009). Multimedia learning (2nd ed.). New York: Cambridge University Press.

Niaz, M. (1995). Progressive transitions from algorithmic to conceptual understanding in student ability to solve chemistry problems: A Lakotasian interpretation. Science Education, 79, 19-36.

Perales, F. y Jiménez, J. (2002). Las ilustraciones en la enseñanza-aprendizaje de las ciencias. Análisis de libros de texto. Enseñanza de las Ciencias, 20, 368-386.

Pozo, J., Gómez Crespo, M., Limón, M. y Sanz Serrano, A. (1991). Procesos cognitivos en la comprensión de la ciencia: las ideas de los adolescentes sobre la química. Madrid: C.I.D.E.

Quílez, J. (2008). Students'and teachers' inability to transfer the molar concentration concept to aqueous equilibrium solutions. The Chemical Educator, 13, 61-66.

Raviolo, A. (2015). Los dibujos esquemáticos en la enseñanza y aprendizaje de las ciencias. Novedades Educativas, 295, 66-70.

Raviolo, A. (2016). Las imágenes en libros de texto universitarios: el capítulo equilibrio químico. Educación en la Química, 22(1), 26-38.

Raviolo, A. (2019). Imágenes y enseñanza de la Química. Aportes de la Teoría cognitiva del aprendizaje multimedia. Educación Química, 30(2), 114-128.

Raviolo, A. y Farré, A. (2018). Razonando con molaridad. Educación en la Química, 24(2), 126-136.

Ryan, S. (2012). Student ratio use and understanding of molarity concepts within solutions chemistry. Ph. D. Dissertation, University of Illinois at Chicago, Chicago.

Solaz, J. (1996). Diagramas: ¿ilustraciones eficaces en la instrucción en ciencias? Educación Química, 7(3), 145-149.

Souza, K. y Porto, P. (2012). Chemistry and chemical education through text and image: Analysis 
of twentieth century textbooks used in Brazilian context. Science \& Education, 21, 705-727.

Sutton, C. (1997). Ideas sobre la ciencia e ideas sobre el lenguaje. Alambique, 12, 8-32. 